\title{
Melanin-producing medullary thyroid carcinoma with transformation to melanoma: A case report
}

\author{
KEI-ICHI YOSHIKAWA ${ }^{1}$, TAKEHIRO TANIMURA ${ }^{1}$, MASAE HOSHI $^{1}$, TATSUYA FUKUMORI ${ }^{1}$, \\ KAZUO SHIMIZU $^{1}$, SHINYA ISHII ${ }^{2}$, HIROYUKI ONOSE ${ }^{2}$, EMIKO YAMADA ${ }^{2}$, YOSHIYUKI SUGISHITA ${ }^{3}$, \\ SHIGEKAZU SUZUKI ${ }^{4}$, MITSUYOSHI HIROKAWA ${ }^{5}$, AKIRA MIYAUCHI $^{6}$ and TETSU YAMADA $^{1}$ \\ Departments of ${ }^{1}$ Surgery, ${ }^{2}$ Internal Medicine, ${ }^{3}$ Laboratory and ${ }^{4}$ Cytology Room, Kanaji Thyroid Hospital, \\ Kita-ku, Tokyo 114-0015; Departments of ${ }^{5}$ Diagnostic Pathology and Cytology and \\ ${ }^{6}$ Surgery, Kuma Hospital, Kobe, Hyogo 650-0011, Japan
}

Received November 27, 2020; Accepted August 13, 2021

DOI: $10.3892 / \mathrm{mco} .2021 .2467$

\begin{abstract}
Only one case of melanoma arising from melanin-producing medullary thyroid carcinoma (MTC) has been reported previously. In the present study, a second such case was reported and compared with the previous one. The patient was an 86-year-old male who presented with a right anterior neck mass. Ultrasound revealed a nodule measuring $49 \times 48 \times 40 \mathrm{~mm}$ in the right lobe of the thyroid. The levels of serum calcitonin $(2,298 \mathrm{pg} / \mathrm{ml})$ and carcinoembryonic antigen $(\mathrm{CEA} ; 27.0 \mathrm{ng} / \mathrm{ml}$ ) were markedly elevated. Aspiration cytology revealed suspected malignant anaplastic thyroid carcinoma and total thyroidectomy without neck nodal dissection was performed. On gross observation, the nodule was well encapsulated, soft, solid and black. Light microscopy indicated that the nodule was composed mainly of large, occasionally huge, pleomorphic cells with a solid or alveolar growth pattern. On immunohistochemistry, these cells were positive for melan-A and S-100 protein, and negative for thyroid transcription factor 1, calcitonin, chromogranin A and CEA. In the subcapsular area, melanin-producing MTC was intimately intermingled with the pleomorphic cells. No primary site of the melanoma was detectable in other organs. At three years after surgery, the patient died due to metastasis of the melanoma to the brain. The previously reported case had no detectable recurrence or distant metastasis up to 11 years
\end{abstract}

Correspondence to: Dr Kei-ichi Yoshikawa, Department of Surgery, Kanaji Thyroid Hospital, 1-5-6 Nakazato, Kita-ku, Tokyo 114-0015, Japan

E-mail:k1yoshikawa@yahoo.co.jp

Abbreviations: MTC, medullary thyroid carcinoma; CEA, carcinoembryonic antigen; ATC, anaplastic thyroid carcinoma; FNAC, fine-needle aspiration cytology; NEC, neuroendocrine carcinoma

Key words: medullary thyroid carcinoma, melanotic variant, melanoma, melanin pigment, melan-A after surgery. In comparison with that case, the present case had a similar morphology but the outcome was poorer. Thus, the prognosis of melanoma that transforms from MTC appears to remain uncertain.

\section{Introduction}

Medullary thyroid carcinoma (MTC), a type of malignant tumor arising from $\mathrm{C}$-cells, is characterized by the production of calcitonin. As only $0.01-0.1 \%$ of total cells in the human thyroid gland are C-cells, MTC is a rare tumor type that accounts for $2-4 \%$ of all malignant thyroid neoplasms. MTC has a more aggressive clinical course than differentiated thyroid cancers and a poorer prognosis. Calcitonin is produced by both normal and neoplastic C-cells and is a specific and highly sensitive biomarker. Neoplastic C-cells also produce carcinoembryonic antigen (CEA). These molecules are widely used markers for diagnosis, prognosis and follow-up of patients with MTC.

MTC may exhibit several, although infrequent, cytoarchitectural variants such as the pseudo-papillary, follicular, spindle-cell, giant-cell, clear-cell, oncocytic, squamous, amphicrine, paraganglioma-like, angiosarcoma-like and small-cell forms (1). In rare cases, MTC may be composed of carcinoma cells containing variable amounts of melanin pigment, being referred to as the melanotic variant of MTC (2) or melanin-producing MTC (3). At our clinic, a case of melanin-producing MTC that had components of melanoma was encountered. To the best of our knowledge, only one such case has been reported previously (4). The second case was reported in the present study and compared with the previous one. Although the previously reported case had no detectable recurrence or distant metastasis up to 11 years after surgery (4), the patient of the present study died due to brain metastasis three years after tumor resection. The present case had a similar morphology to the previously reported one but the outcome was poorer.

\section{Case report}

Ultrasound. Ultrasonographic imaging was performed using an SSD-3500 (Hitachi-Aloka) with a 7.5-10 MHz linear probe. 
Table I. Clinical findings and data of preoperative biochemical tests.

\begin{tabular}{lccc}
\hline Item & Present case & Previous case $^{\mathrm{a}}$ & Normal range $^{-}$ \\
\hline Age, years & 86 & 66 & - \\
Sex & Male & Female & - \\
Prognosis after surgery, years & 3 & 11 & - \\
Biochemical tests & & & \\
Thyroid-stimulating hormone, $\mu \mathrm{IU} / \mathrm{ml}$ & 2.84 & - & $0.35-3.80$ \\
Free thyroxine, $\mathrm{ng} / \mathrm{dl}$ & 1.2 & - & $0.7-1.7$ \\
Free triiodothyronine, pg/ml & 3.1 & - & $2.2-4.1$ \\
Anti-thyroglobulin antibody, $\mathrm{U} / \mathrm{ml}$ & $<15.0$ & - & $\leq 40$ \\
Anti-thyroid peroxidase antibody, $\mathrm{U} / \mathrm{ml}$ & $<28.0$ & - & $\leq 50$ \\
Thyroglobulin, ng/ml & 37.9 & - & $\leq 32.8$ \\
Calcitonin, $\mathrm{pg} / \mathrm{ml}$ & 2,298 & 960 & $\leq 5.15$ \\
CEA, ng/ml & 27.0 & 6.1 & $\leq 5.0$ \\
\hline
\end{tabular}

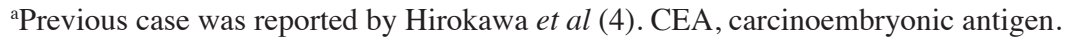

Imaging was performed in B-mode and the focus was set to $2 \mathrm{~cm}$. B-mode gain was adjusted by the auto-optimizer. Both transverse and longitudinal sectional images were obtained.

Computed tomography $(C T)$. Both plain and contrast-enhanced CT were performed using an ECLOS 16S (Hitachi Medico). Iohexol (Omunipaque; GE Healthcare Pharma; iodine concentration, $300 \mathrm{mg} / \mathrm{ml}$ ) was used as the contrast medium and enhanced CT was recorded $80 \mathrm{sec}$ after injection of the contrast medium. CT scans were performed with a helical type under the following conditions: Voltage, $120 \mathrm{kV}$; current, $250 \mathrm{~mA}$; slice thickness, $5 \mathrm{~mm}$; slice interval, $5 \mathrm{~mm}$; imaging time, $0.8 \mathrm{sec}$.

Fine-needle aspiration cytology (FNAC). FNAC of the nodule was performed with a $22 \mathrm{G}$ needle under ultrasound guidance. After Papanicolaou staining (Muto Pure Chemicals Co.) (5) of the specimen, the diagnosis was made according to the Bethesda reporting system (6).

Pathology and immunohistochemical (IHC) analysis. The resected whole thyroid organ was fixed for $\sim 24 \mathrm{~h}$ using $10 \%$ formalin neutral buffered solution. Subsequently, it was embedded in paraffin according to the usual method after dehydration using ethanol. Paraffin sections $(3 \mu \mathrm{m})$ were prepared for IHC analysis using primary antibodies for the detection of melan-A (cat. no. A103; diluted 1:100), HMB-45 (cat. no. M0634; diluted 1:50), S-100 protein (cat. no. A5114; polyclonal; diluted $1: 1,500)$, thyroid transcription factor 1 (TTF-1; cat. no. 8G7G3/1; diluted 1:100), calcitonin (polyclonal; cat. no. IR515; diluted 1:10), Ki-67 (MIB-1; cat. no. M7240; diluted 1:200), chromogranin A (DAK-A3; cat. no. M0869; diluted 1:400; all from Dako; Agilent Technologies, Inc.), CEA (COL-1; cat. no. 413212; diluted 1:4; Histofine) and BRAF V600E (cat. no. 31-1042-00-S, RM8; diluted 1:100; RevMAb Biosciences). Epitope retrieval was performed according to the manufacturer's recommended procedure for each primary antibody. Prior to staining of the sections, endogenous peroxidase activity was blocked using $3 \% \mathrm{H}_{2} \mathrm{O}_{2}$. After incubation with the primary antibody at room temperature for $2 \mathrm{~h}$, visualization was performed using a polymer IHC detection system and diaminobenzidine chromogen as a substrate (Envision Kit; Dako; Agilent Technologies, Inc.). Visualization of BRAF V600E was performed using 3-amino-9-ethyl carbazole. Sections were counterstained with hematoxylin.

Clinical findings. An 86-year-old male patient presented with a right anterior neck mass that had been increasing in size (August 2012; Kanaji Thyroid Hospital, Tokyo, Japan). The patient had first noticed the mass 3 years previously and undergone ultrasound examination and FNAC of the thyroid, but no treatments had been received. The patient had no family history of multiple endocrine neoplasia, neither type $2 \mathrm{~A}$ or type $2 \mathrm{~B}$. Physical examination revealed an elastic hard and mobile mass $5 \mathrm{~cm}$ in diameter in the right lobe of the thyroid. No enlarged lymph nodes were palpable in the neck region. Presurgical physiological data (blood parameters) are presented in Table I. Thyroid function tests yielded normal values (Table I). The thyroglobulin level was $37.9 \mathrm{ng} / \mathrm{ml}$ (Table I) and the levels of serum calcitonin and CEA were markedly elevated (Table I). Ultrasound revealed a nodule measuring $49 \times 48 \times 40 \mathrm{~mm}$ in the right lobe of the thyroid. It was well-defined, hypoechoic and heterogeneous (Fig. 1A). On CT scans, the nodule appeared homogeneous with peripheral enhancement (Fig. 1B and C). The imaging findings were interpreted as suspicious for follicular tumor. FNAC performed on the nodule revealed numerous large pleomorphic cells without specific structure, and therefore, anaplastic thyroid carcinoma (ATC) was suspected (Fig. 2). The patient underwent total thyroidectomy without neck nodal dissection at Kanaji Thyroid Hospital (Tokyo, Japan). As the pathological diagnosis was melanoma, thyroid metastasis of melanoma was considered and an extensive examination at the dermatology department of another hospital was performed after the operation, but no primary site of the melanoma was detected. Subsequently, the serum calcitonin and CEA levels returned to normal. However, a brain tumor, which was 
A

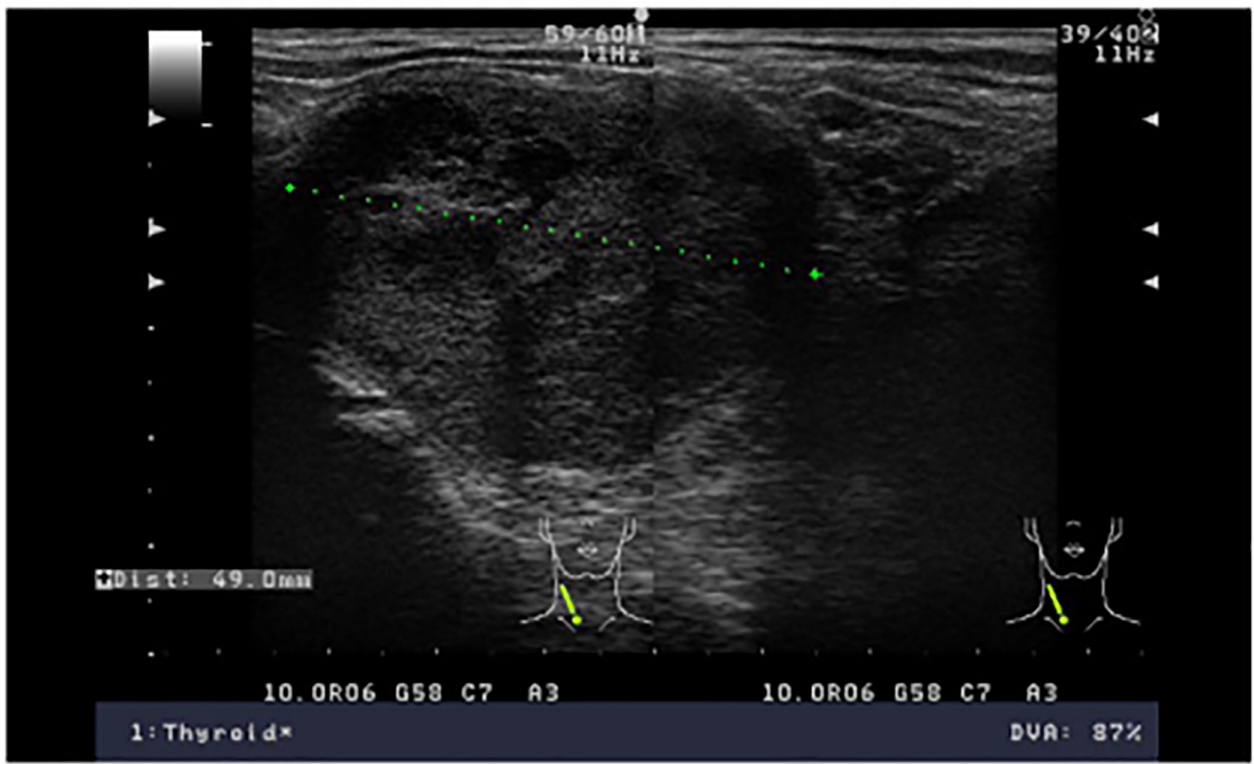

$\mathrm{B}$

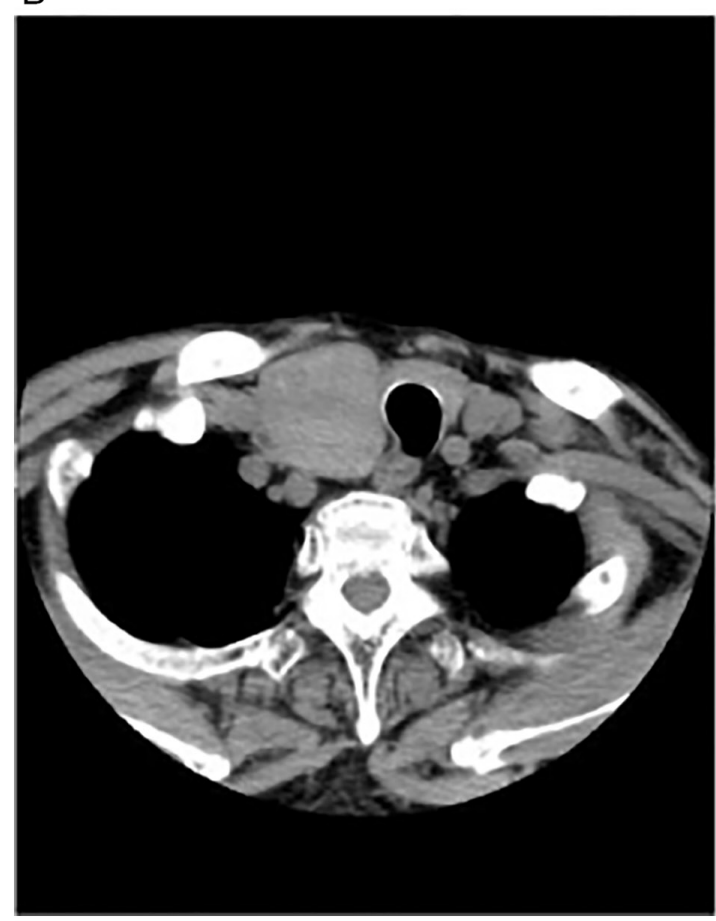

C

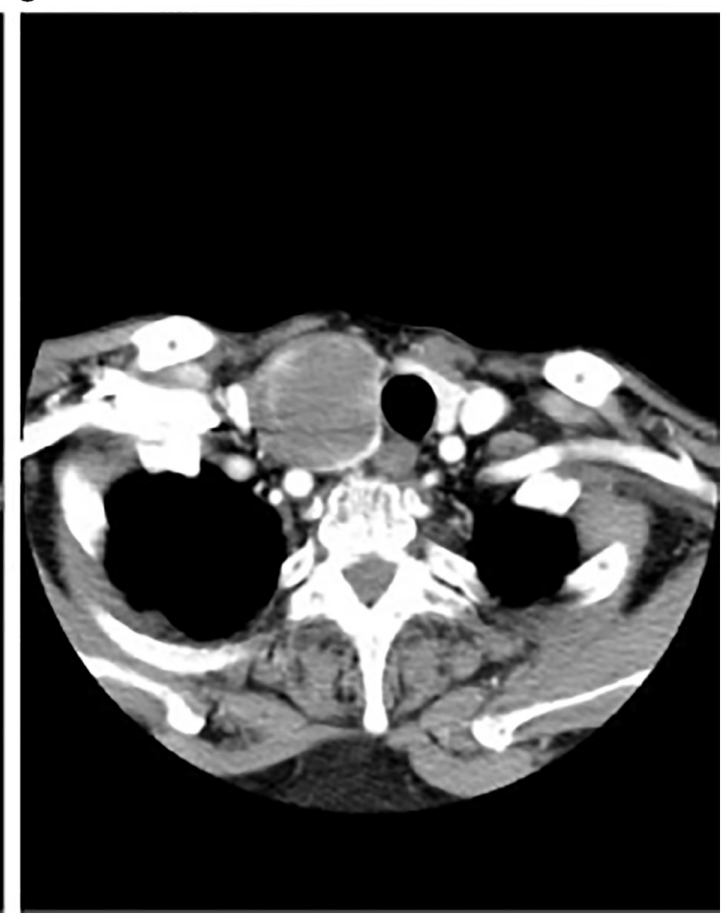

Figure 1. (A) Ultrasonography of the neck (longitudinal sectional image), indicating a well-defined, hypoechoic mass in the right lobe of the thyroid. (B and C) Computed tomography scan of the neck, displaying (B) a well-demarcated, homogeneous mass (C) with peripheral enhancement.

assumed to be metastasis of the melanoma, had occurred and the patient died three years after the operation. Although no definitive diagnosis was obtained regarding whether the brain tumor was metastasis of the melanoma or a primary tumor such as glioma because no autopsy was performed, the clinical course led to the assumption that the cause of death was brain metastasis of the melanoma.

Pathological findings. On gross examination, the nodule measured $5.0 \mathrm{~cm}$ in maximum diameter. It was well encapsulated, soft and located in the right lobe of the thyroid. The cut surface was solid and black (Fig. 3).
Light microscopy indicated that the nodule was composed mainly of large, occasionally huge, pleomorphic cells with a solid or alveolar growth pattern (Fig. 4A) and necrotic areas. The nuclei of the pleomorphic cells were large and hyperchromatic. Intranuclear cytoplasmic inclusions, multinucleation, irregularly shaped nuclei and mitotic figures were apparent. The nucleoli were large, prominent and frequently had a perinucleolar halo. The cytoplasm was abundant and eosinophilic. Most of the atypical cells contained melanin pigment, which frequently occupied most of the cytoplasm. The morphology of the pleomorphic cells was consistent with that of ATC, except for the presence of melanin pigment. 
Table II. Immunohistochemical findings of two cases of pigmented medullary carcinoma with malignant melanoma.

\begin{tabular}{|c|c|c|c|c|}
\hline \multirow[b]{2}{*}{ Antibodies } & \multicolumn{2}{|c|}{ Present case } & \multicolumn{2}{|c|}{ Previous case $^{\mathrm{a}}$} \\
\hline & $\begin{array}{c}\text { Medullary } \\
\text { carcinoma cells }\end{array}$ & $\begin{array}{l}\text { Melanoma } \\
\text { cells }\end{array}$ & $\begin{array}{c}\text { Medullary } \\
\text { carcinoma cells }\end{array}$ & $\begin{array}{l}\text { Melanoma } \\
\text { cells }\end{array}$ \\
\hline Melan-A & - & + & - & + \\
\hline HMB-45 & - & + & - & + \\
\hline S-100 protein & - & + & - & + \\
\hline TTF-1 & + & - & $+($ focal $)$ & - \\
\hline Calcitonin & + & - & + & $+($ focal $)$ \\
\hline Chromogranin A & + & - & + & $+($ focal $)$ \\
\hline CEA & + & - & + & - \\
\hline BRAF V600E & - & - & l & l \\
\hline Ki-67 & $<3 \%$ & $>80 \%$ & $<1 \%$ & $<60 \%$ \\
\hline
\end{tabular}

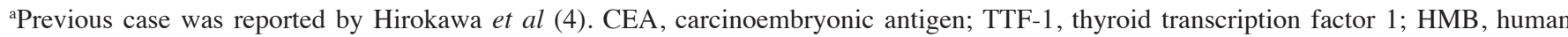
melanoma black.

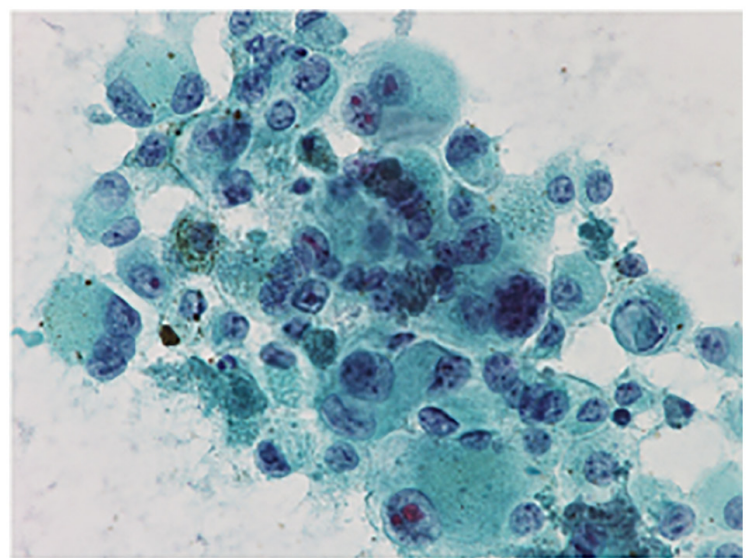

Figure 2. Fine-needle aspiration cytology revealed discohesive large pleomorphic atypical cells and certain cells contained melanin pigment (magnification, $\mathrm{x} 400$ ).

Aggregated macrophages containing a large amount of melanin pigment were present in the areas occupied by the pleomorphic cells. In the subcapsular areas, solid or lobular growth of small spindle cells was evident (Fig. 4B). These cells had granular chromatin but nuclear pleomorphism was not apparent. The cytoplasm was scant and amphophilic. A small to moderate amount of melanin pigment was present in the cytoplasm. The large pleomorphic cells and small spindle cells were intimately intermingled and neither exhibited capsular or vascular invasion. No amyloid deposition was evident throughout the tumor.

IHC revealed that the large pleomorphic cells were positive for melan-A (Fig. 4C), HMB-45 (Fig. 4D) and S-100 protein, and negative for TTF-1 (Fig. 4E), calcitonin (Fig. 4F), chromogranin A (Fig. 4G), CEA (Fig. 4H) and BRAF V600E (Fig. 4I). The small spindle cells were positive for TTF-1 (Fig. 4E), calcitonin (Fig. 4F), chromogranin A (Fig. 4G) and CEA (Fig. 4H). The Ki-67 labeling indices of the pleomorphic cells and spindle cells were $>80$ and $<3 \%$, respectively. A

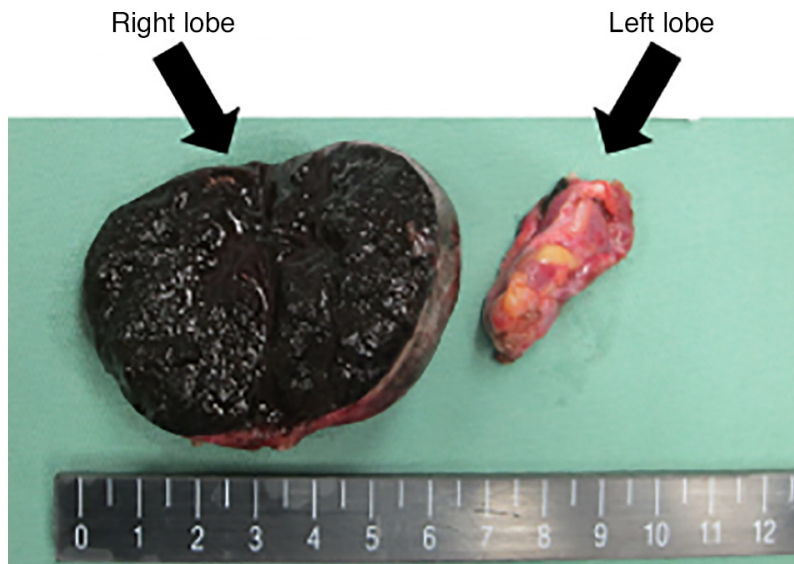

Figure 3. Resected thyroid tissues. An encapsulated black solid nodule was present in the right lobe, while the left lobe was comprised of normal thyroid tissue. The scale in the photo is in centimeters.

comparison of the IHC results between the present case and previous case (4) is provided in Table II.

\section{Discussion}

The thyroid tumor of the present case was encapsulated and composed of two types of carcinoma cells containing melanin pigments: Large pleomorphic cells and small spindle cells, the former accounting for the majority. Morphologically, the large pleomorphic cells were similar to those of ATC except for the presence of melanin pigment. On IHC analysis, the cells were positive for melan-A and S-100 protein, being consistent with melanoma. The small spindle cells were positive for TTF-1, calcitonin, chromogranin and CEA, suggesting the diagnosis of MTC. The presence of spindle cells with melanin pigment was consistent with melanin-producing MTC.

As to the melanoma component in the present case, either a primary or a metastatic origin may be considered. Metastases to the thyroid gland are not unusual and frequent sites for 

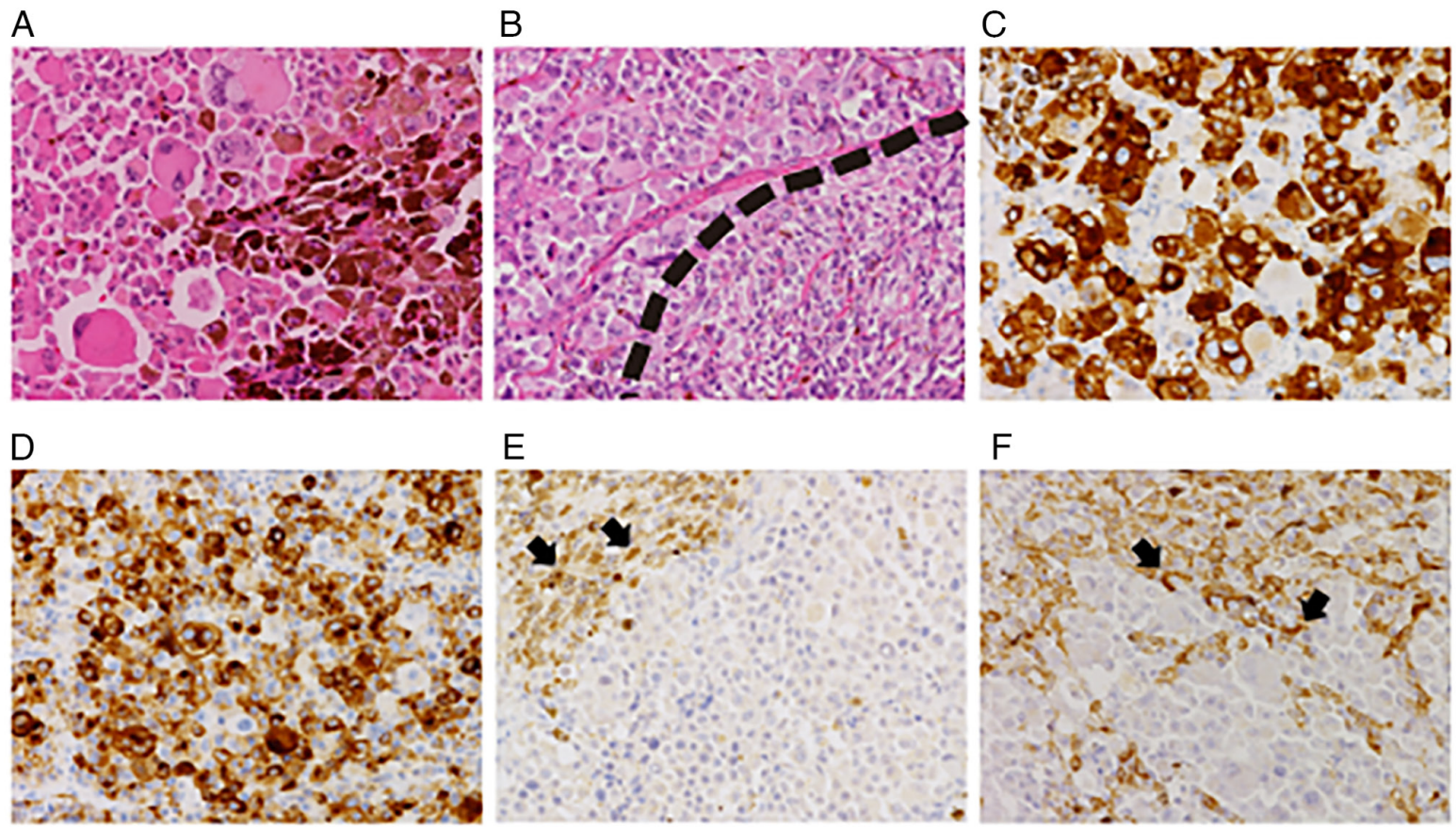

E
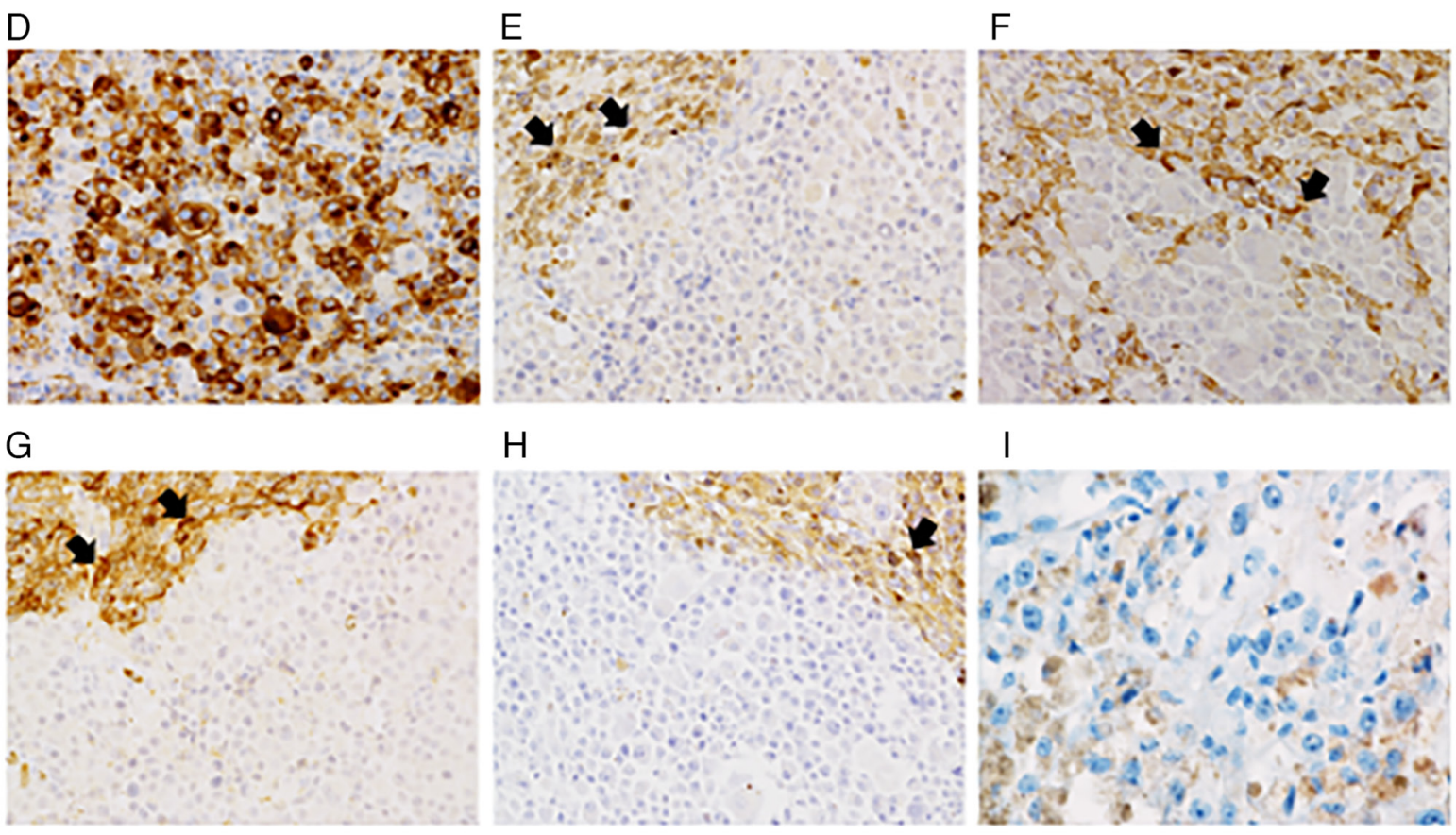

\section{I}

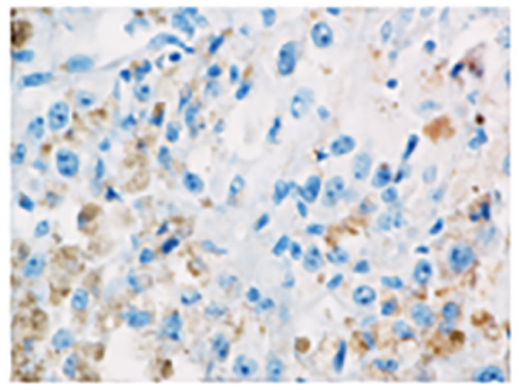

Figure 4. (A) Representative HE staining image. Large pleomorphic melanoma cells exhibit a diffuse growth pattern and contain melanin pigment. (B) Representative HE staining image. Melanoma cells (upper left) and medullary carcinoma cells (lower right) are intimately intermingled. Medullary carcinoma cells also contained melanin pigment. (C-I) On immunohistochemistry, melanoma cells were positive for (C) melan-A and (D) HMB-45 and negative for (E) TTF-1, (F) calcitonin, (G) chromogranin A, (H) CEA and (I) BRAF V600E. Visualization of BRAF V600E was performed using AEC. AEC visualization develops a red color. Brown material in I are melanin pigments. Medullary carcinoma cells were positive for TTF-1, calcitonin, chromogranin A and CEA, as indicated by the arrows (magnification, x200). CEA, carcinoembryonic antigen; TTF-1, thyroid transcription factor 1; HMB, human melanoma black; AEC, 3-amino-9-ethyl carbazole.

primary tumors include the kidney (22\%), lung (22\%) and head and neck (12\%) (7). Melanoma is able to metastasize to the thyroid (8). However, in an extensive examination of other organs, no primary melanoma lesion or other metastatic lesions were detected. Neuroendocrine carcinoma (NEC) may exhibit melanocytic differentiation (9-13). MTC is a form of NEC and is well known to exhibit melanocytic differentiation (2,14-19). In the present case, the fact that both the MTC and melanoma contained melanin pigment and were intermingled without the formation of a front suggested an intimate relationship between the two. In the only previous case of melanoma arising in MTC reported so far, the two elements described by Hirokawa et al (4) had a morphology and distribution similar to those in the present case. On this basis, it was concluded that in the present case, the MTC had undergone transformation to melanoma.

The previous case also had a high Ki-67 labeling index and extensive nodal metastasis. However, no detectable recurrence or distant metastasis was evident up to 11 years after surgery.
The prognosis of the anaplastic variant of MTC composed of large pleomorphic cells resembling ATC is better than that of ATC (19). However, the patient of the present study died due to brain metastasis three years after tumor resection. BRAF mutation is present in $\sim 50 \%$ of all melanomas (20) and is linked to a higher incidence of brain metastasis and shorter survival time (21). Despite the fact that the present case had brain metastases and a poor outcome, BRAF mutation was not detected. In the case reported by Hirokawa et al (4), BRAF mutations were not measured. Thus, the prognosis of melanoma that has transformed from MTC still appears to be uncertain.

In conclusion, the present case of melanoma transformed from MTC is the second of its type to have been reported. In comparison with the case reported previously, the morphology of the present case was similar, but the outcome was poorer. Therefore, it is not possible to make any definitive conclusions regarding the prognosis of this disease until further cases have accumulated. 


\section{Acknowledgements}

Not applicable.

\section{Funding}

No funding was received.

\section{Availability of data and materials}

The data analysed during the present study are available from the corresponding author upon reasonable request.

\section{Authors' contributions}

$\mathrm{KY}$ was the major contributor in the conception and design of this case report and writing of the manuscript. KY, TT, MH, TF, KS, SI, HO, EY, YS, SS and TY were contributors in the acquisition of data. KY, MH, AM and TY analyzed and interpreted the data. All authors read and approved the final manuscript. KY and MH checked and approved the raw data.

\section{Ethics approval and consent to participate}

All samples were collected after obtaining informed consent from the patient and any personally identifiable information was kept confidential in this study.

\section{Patient consent for publication}

The daughter of the patient provided written informed consent for the publication of clinical data and images.

\section{Competing interests}

The authors declare that they have no competing interests.

\section{References}

1. Lloyd RV, Osamura RY, Klöppel G and Rosai J (eds): WHO Classification of Tumours of Endocrine Organs. IARC, Lyon, pp108-113, 2017.

2. de Lima MA, Dias Medeiros J, Rodrigues Da Cunha L, de Cássia Caldas Pessôa R, Silveira Tavares F, de Fátima Borges M and Marinho EO: Cytological aspects of melanotic variant of medullary thyroid carcinoma. Diagn Cytopathol 24: 206-208, 2001.
3. Eng HL and Chen WJ: Melanin-producing medullary carcinoma of the thyroid gland. Arch Pathol Lab Med 113: 377-380, 1989.

4. Hirokawa M, Miyauchi A, Otsuru M and Daa T: Malignant melanoma arising in melanin-producing medullary thyroid carcinoma. Int J Surg Case Rep 20: 118-122, 2016.

5. Chantziantoniou N, Donnelly AD, Mukherjee M, Boon ME and Austin RM: Inception and development of the papanicolaou stain method. Acta Cytol 61: 266-280, 2017.

6. Cibas ES and Ali SZ: The 2017 Bethesda system for reporting thyroid cytopathology. Thyroid 27: 1341-1346, 2017.

7. Hegerova L, Griebeler ML, Reynolds JP, Henry MR and Gharib H: Metastasis to the thyroid gland: Report of a large series from the Mayo clinic. Am J Clin Oncol 38: 338-342, 2015.

8. Pusztaszeri M, Wang H, Cibas ES, Powers CN, Bongiovanni M Ali S, Khurana KK, Michaels PJ and Faquin WC: Fine-needle aspiration biopsy of secondary neoplasms of the thyroid gland: A multi-institutional study of 62 cases. Cancer Cytopathol 123: 19-29, 2015.

9. Lack EE, Kim H and Reed K: Pigmented ('black') extraadrenal paraganglioma. Am J Surg Pathol 22: 265-269, 1998.

10. Bellezza G, Giansanti M, Cavaliere A and Sidoni A: Pigmented 'black' pheochromocytoma of the adrenal gland: A case report and review of the literature. Arch Pathl Lab Med 128: e125-e128, 2004.

11. Klemm KM, Moran CA and Suster S: Pigmented thymic carcinoids: A clinicopathological and immunohistochemical study of two cases. Mod Pathol 12: 946-948, 1999.

12. Eyden B, Pandit D and Banerjee SS: Malignant melanoma with neuroendocrine differentiation: Clinical, histological, immunohistochemical and ultrastructural featyres of three cases. Histopathology 47: 402-409, 2005.

13. Pilozzi E, Cacchi C, Di Napoli A, Pini B, Duranti E, D'Andrilli A and Ruco L: Primary malignant tumour of the lung with neuroendocrine and melanoma differentiation. Virchows Arch 459: 239-243, 2011.

14. Karaarslan S, Nur Yurum F, Ebru Pala E, Ortac R and Husnu Bugdayci M: The relationship of melanocytic differentiation with prognostic markers in medullary thyroid carcinomas. Pathol Res Pract 211: 356-360, 2015.

15. Marcus JN, Dise CA and LiVolci VA: Melanin production in medullary thyroid carcinoma. Cancer 49: 2518-2526, 1982.

16. Ikeda T, Satoh M, Azuma K, Sawada N and Mori M: Medullary thyroid carcinoma with a paraganglioma-like pattern and melanin production: A case report with ultrastructural and immunohistochemical studies. Arch Pathol Lab Med 122: 555-558, 1998.

17. Ben Romdhane K, Khattech R, Ben Othman M, Gamoudi A Ammar A and Cammoun M: Melanin production in medullary thyroid carcinoma. Histpathology 27: 569-571, 1995.

18. Mohamad I, Zainuddin N, Zawawi N and Naik VR: Melanocytic variant of medullary thyroid carcinoma in a previously treated papillary carcinoma patient. Ann Acad Med Singap 40: 300-301, 2011.

19. Mendelsohn G, Baylin SB, Binger SH, Wells SA Jr and Eggleston JC: Anaplastic variants of medullary thyroid carcinoma: A light-microscopic and immunohistochemical study. Am J Surg Pathl 4: 333-341, 1980.

20. Shtivelman E, Davies MA, Hwu P, Yang J, Lotem M, Oren M, Flaherty KT and Fisher DE: Pathways and therapeutic targets in melanoma. Oncotarget 7: 1701-1752, 2014.

21. Redmer T: Deciphering mechanisms of brain metastasis in melanoma-the gist of the matter. Mol Cancer 17: 106, 2018. 